\title{
REFRIGERATOR AND SOLENOID RUN SUMMARY \\ AUGUST/SEPTEMBER 1999
}

D-ZERO ENGINEERING NOTE\# 3823.115-EN-514

September 20, 1999

Author: Russ Rucinski

PPD/ETT/D-Zero Upgrade project 


\begin{abstract}
The helium refrigerator was cooled down and operated for the third time since its installation. D-Zero's 2 Tesla superconducting solenoid was cooled down and operated for its second time since its installation into the D-Zero detector. This engineering note summarizes the cryogenic aspects of the test run and performance measurements made.
\end{abstract}

\title{
Goals and Results Summary
}

The main purpose of this run was to do field mapping of the solenoid with different combinations of field polarity on the Solenoid and CF iron magnets. This was accomplished.

A second purpose was to test the lower field joint repair that was done in January 1999. This field joint had a measurable voltage drop across the soldered bus splice. The repair was an undoing of the joint, extensive cleaning of the bus, and then welding the splice. The repair was successful, no voltage drop was measured and the magnet behaved nicely.

A parasitic purpose was to get some operating time on the refrigerator, measure the refrigeration performance, and measure the heat leak in the VLPC lines mounted on the detector platform. Refrigerator performance was spot checked, and was found to be 60 watts $(10 \%)$ less than generic operating curves. At this level of performance, the operating margin for the full solenoid and VLPC system will be 75 watts (15\%) which is somewhat uncomfortable from an operational stand point.

The VLPC lines were operated and heat leak numbers of around 40 watts was measured for each pipe section including the supply u-tubes to the detector, the bayonet can, valve box on the platform and the piping back to the refrigerator valve box.

Another purpose of the test run was to test the compatibility of other detector components with the new central magnetic field environment. I do not know the results of these tests.

\section{Refrigerator past history and improvements}

The refrigerator was first operated in June 1997 (reference EN-457). It was cooled down and operated again in September 1998 for the Solenoid's commissioning run (reference EN-503). In between each run, some improvements have been made. Between the last run and this run the improvements were:

1. EV-2000-H was moved downstream of the inventory control valves, LOSUC, HISUC, HIDIS. This allows gas to be circulated with the heat exchanger isolated.

2. A new manual isolation valve, trapped volume relief, and new PV-2713-N fermi valve has been added upstream of our LN2 subcooler pot to remedy a leaky valve.

3. The bullet size in DOBEVXLN from a $\mathrm{Cv}=2.0$ to a $\mathrm{Cv}=0.5$ for better control. 
3. The bullet size in DOBEVXLN from a $\mathrm{Cv}=2.0$ to a $\mathrm{Cv}=0.5$ for better control.

4. The VLPC transfer line on the detector was completed up to a turn around boot located where the future cryostats will be. .

5. FTCLF2 was replaced with a new controller. The old FTCLF2 was sent out for re-calibration.

\section{Run Summary}

The refrigerator was pumped and backfilled July $21-23$. The refrigerator and solenoid cool down took place simultaneously starting on Tuesday July 27 . We made 1000 liters of liquid helium by Thursday July 29 . It was a very hot summer and electricity demand was at record levels. Fermilab voluntarily chose to reduce electricity consumption, so for the weekend period July 30-August 2, we turned off the refrigerator's 250 horsepower Mycom compressor. Cooldown resumed on August 2 and the magnet was superconducting on August $4^{\text {th }}$. See Figures 1 and 2 for a historical trend of the refrigerator and solenoid cool downs. Figure 3 is a reference historical trend of the first Solenoid cool down.

Lead flow controller 2 problem

We had some problem with lead flow controller FTCLF2 for the first part of the run. The brand new controller did not operate properly. It was promptly replaced with the old FTCLF2 which had been recalibrated since the last run. This flow controller responded linearly with control signal but had a drifting offset. Numerous computer re-scaling attempts were made, only to have drift in a few days time cause the leads to run to warm or too cold. At least twice the top of the leads got so cold that the o-rings froze causing a big cold helium leak. The first time the leak went unnoticed overnight. The plexiglass purge box was encased in ice in the morning. I did note however that frost was minimal inside the box. An autodialer computer alarm was added after this event and after that, if the leads got below $200 \mathrm{~K}$ an automated call was made and the situation rectified within an hour. Attention to the leads was required by the solenoid operators for this trouble period. Eventually the special function computer program was modified to add a proportional loop to the automated set point which ramps according to magnet current. The process variable for the proportional aspect was the lead temperature at $240 \mathrm{~K}$. The lead was again automatic and functional after this change. Repair of the controllers is in progress after the run.

\section{Gas leak noticed}

It was noticed that we were losing gas during the run. Low pressure storage pressure was dropping at an average of $-8.2 \mathrm{psi} /$ day and trending showed DOFSTOR was an average of $-0.18 \mathrm{~g} / \mathrm{s}=138 \mathrm{scfh}$ helium. The $-8.2 \mathrm{psi} /$ day is consistent with $-0.18 \mathrm{~g} / \mathrm{s}$. The leak was discovered/confirmed on August 28. Up until that date we had attributed our gas loss to the current lead o-ring leaks, heat exchanger deriming and losses during loss of Mycom during power reductions. Leak hunting was done which include the suction relief valve, replacement of weeping relief, SV-2113, and a negative check on the heat exchanger LN2 pot exhaust with a Matheson $\circledast$ Leak hunter. On September 7 we switched from Mycom 2 


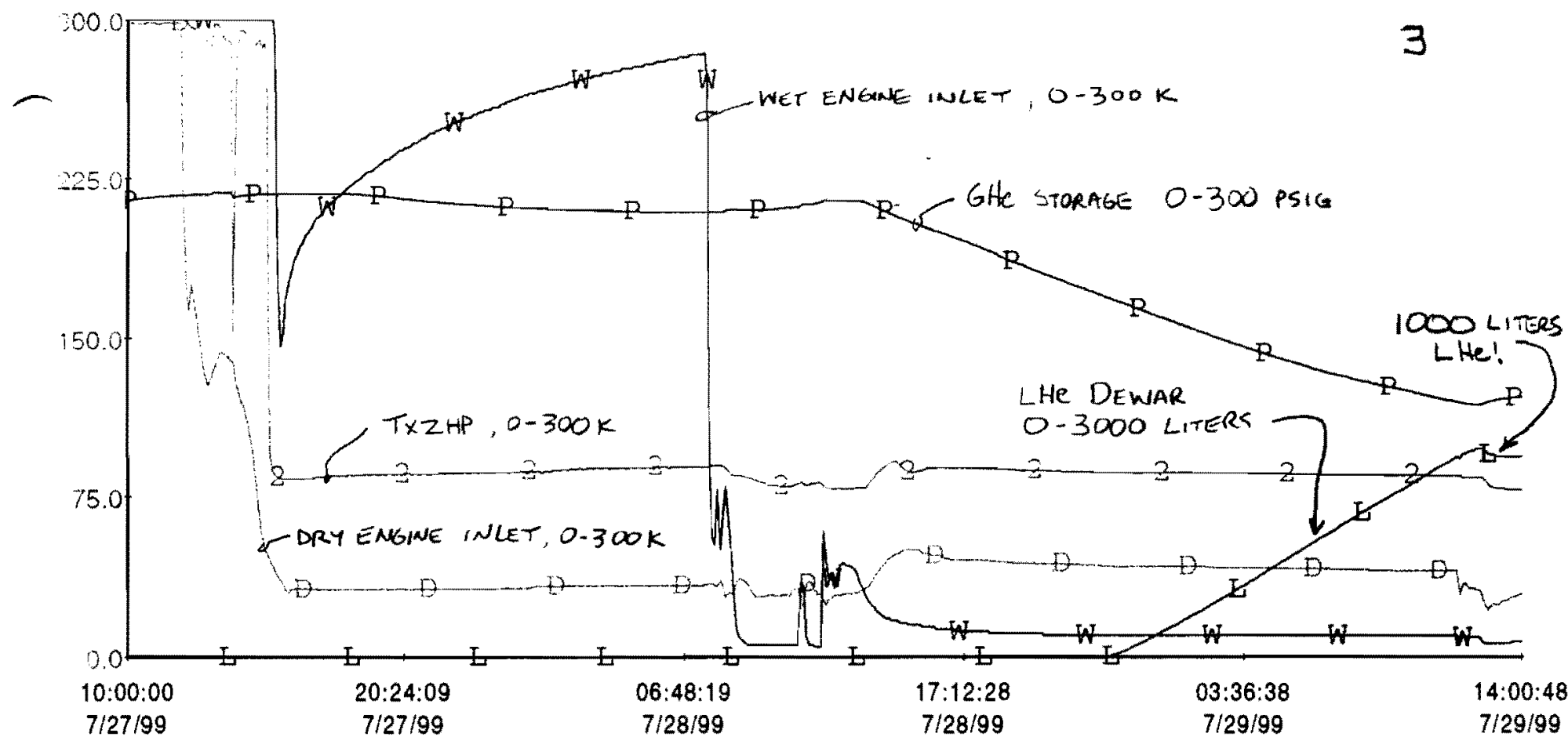

— D DO_CCRS2::DO_CCRS2:DOBPSTORH.F_CV GHe storage vessel pressure

122.0

- - _ _CPS2:DO_CCRS:DOBTY

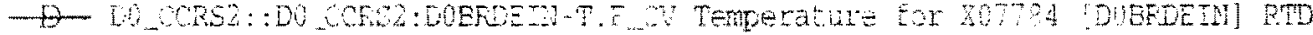

W DO_CCRS2::D0_CCRS2:DOBRWEIN-T.F_CV Temperature for X03605 (D0BRWEIN) RTD

3.3

I DO_CCRS2::DO_CCRS2:LHE-VOL.F_CV LHe Dewar volume based on diff. pressure 937

REFRIGERATOR COOL DOWN JULY 1999

Figure 1 
50.0 SUPPORT CK.

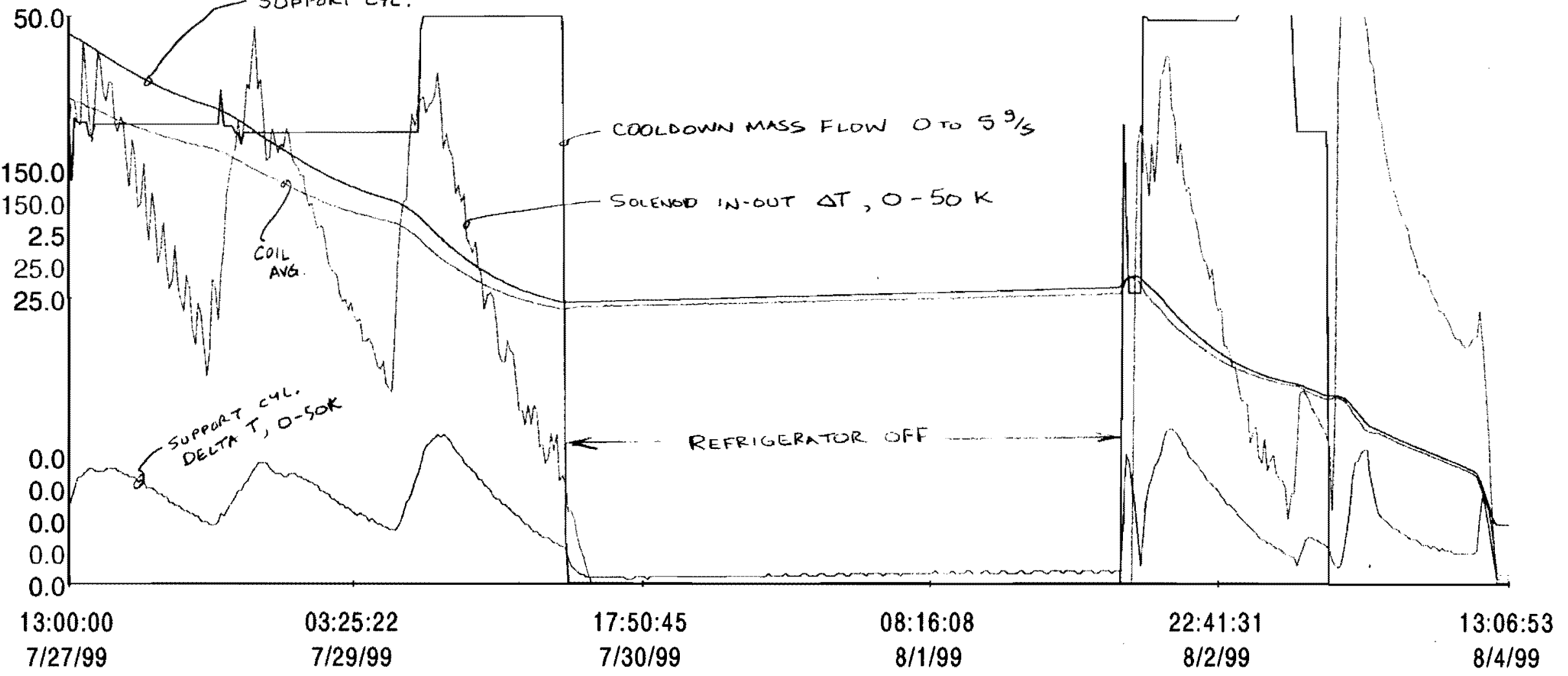

DO_CCRS2 : :DO_CCRS2 : PLAT_OSC_AVE.F_CV

DO_CCRS2::DO_CCRS2:COILAVE3.F_CV AVERAGE TEMP FOR 3 COIL

31.2

DO_CCRS2::DO_CCRS2:FT-2040-H.F_CV High pressure helium to subcooler

- D _CCRS2::DO_CCKS2:COIL_HEOUT-IN.F_CV Solenoid He Out - He In Delta Temp.

- DO_CCRS2::D0_CCRS2:0SC_PLAT_DELTA_T.F_CV Sol support Cyl Delta Temp

\section{Solenoid}

COOLOOWN OVERVIEW FALL 1999




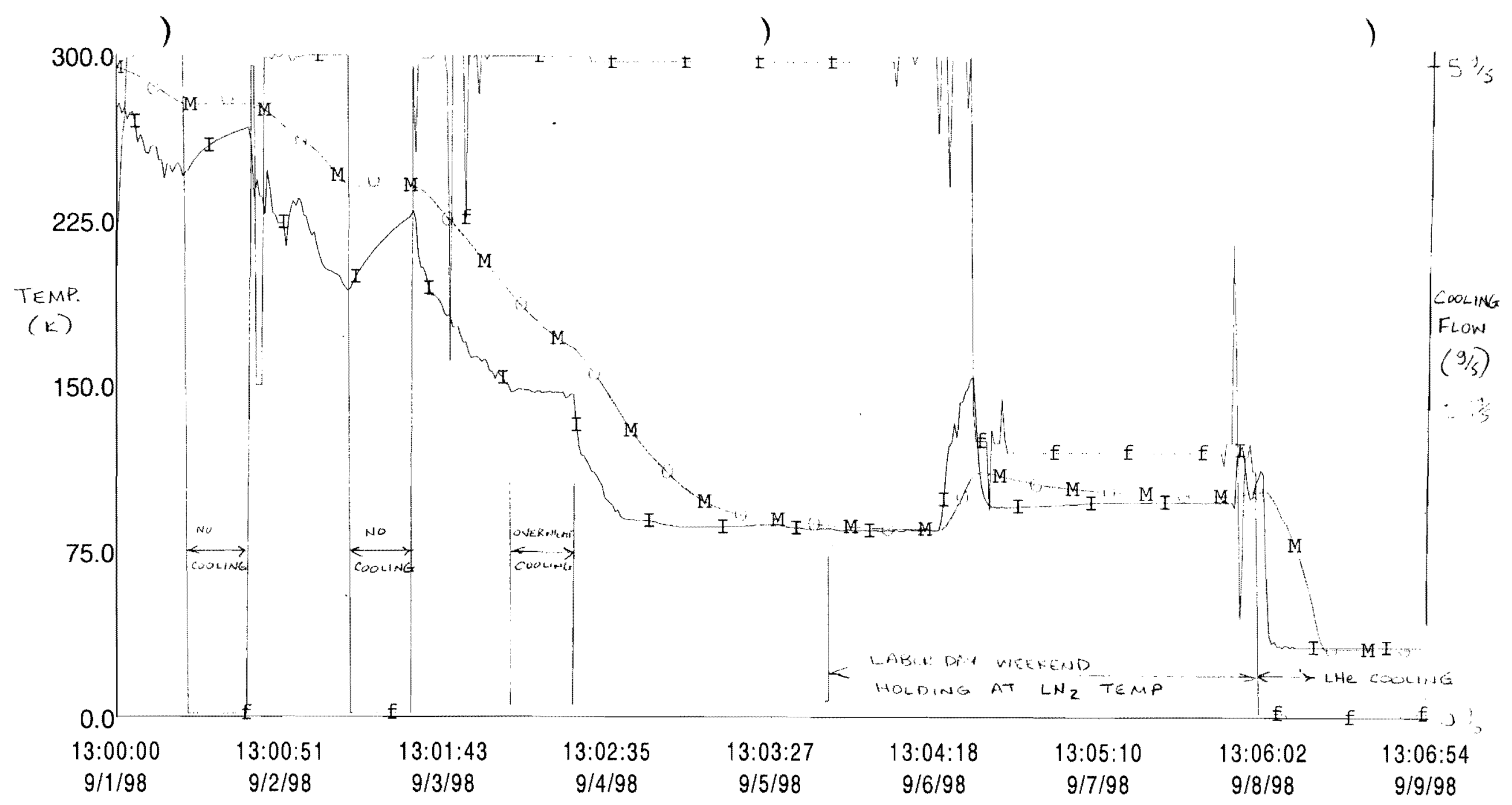

-M-DO_CCRS2::D0_CCRS2:PLAT_OSC_AVE.F_CV (MACNET)

I DO_CCRS2::D0_CCRS2:TP3208H-T.F_CV Temperature for TP-3208-H (IN)

89.3

86.9

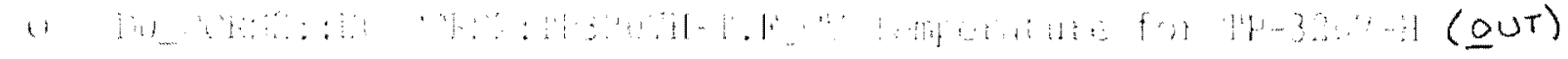

- E D0_CCRS2::D0_CCRS2:FT-2040-H.F_CV High pressure helium to subcooler (ELow) 5.0

Magnet Cooldown $9 / 98$ 
( $100 \%$ loaded) to Mycom 1 (not fully loaded) and the leak was reduced to $-0.04 \mathrm{~g} / \mathrm{s}$. I went back to Mycom 2 and the leak was still reduced or gone. Loading did not seem to be directly related. One theory is that during the switching of the Mycoms, when the system saw wide pressure swings, (suction went negative in fact) something sealed. Another theory is that there was some dynamic gas leak in Mycom 2 that somehow repaired itself during the shut down of the unit. We added about 100,000 cubic feet of gas helium to low pressure storage. The gas was supplied from our recovery system at Lab 3. The gas would have been sold back to BOC for about $\$ 4000$ had we not used it.

\section{Contamination problems}

The refrigerator suffered a sudden contamination problem on August 18. The cause of the problem was the new VLPC detector transfer lines. Two 5/8" dia. lines about 100 feet long did not get a good pump and backfill during the initial refrigerator clean up due to check valves in the line and closed valves. We were running without a helium purifier.

The contamination plated out in the first 3 heat exchangers. The temperatures in the heat exchanger rose 10 to 15 Kelvin. See Figure 4 . We derimed the heat exchanger the next day with contamination getting purged to vent. Shortly after the recovery we borrowed a mobile helium purifier which we used until September 10 .

On the last night of the run, September 16, we experienced the same sort of problem which still puzzles me somewhat. The VLPC transfer lines were being measured for heat leak beginning September 15 . This involved flowing $80 \mathrm{~K}$ gas helium from the cooldown heat exchanger through all the VLPC lines, and then to suction through the cooldown return lines. Everything was fine until 15:00 on September 16. At precisely the time I valved off the cool down supply and valved on the liquid helium supply through u-tube He-311, the refrigerator showed problems. Note that the return path to suction was still the same at that time for more than an hour. See Figure 5. The only difference was He311 was in the flow path. This short line surely should have been swept clean when I flowed liquid through it before on August 18 when we had problems. I checked the vacuum on He-311. It was less than a micron cold and 75 microns warm. I do not understand the problem at this time. Luckily solenoid mapping was completed just before we lost our liquid inventory. We never did recover and make liquid after this. We shut down the refrigerator at 13:00 on September 17. D-Zero is building a permanently stationed full compressor flow helium purifier which will become part of our system to solve future contamination problems.

\section{VLPC transfer line heat leak measurements}

The liquid nitrogen shields were cooled prior to measuring the heat leak on the helium lines. The flow rate through the lines was controlled by PV-2013-H and measured with FT-2013-H at the cool down heat exchanger. The temperature out of the cool down heat exchanger ( 80 to $90 \mathrm{~K}$ ), at the supply can to the detector, and at the return refrigerator valve box were trended and were used to calculate the heat leak values. The supply flow was equally divided through the East and West lines. The basic equation is $\mathrm{Q}=\mathrm{Mdot}^{*} \mathrm{Cp} *$ (Temperature rise). 


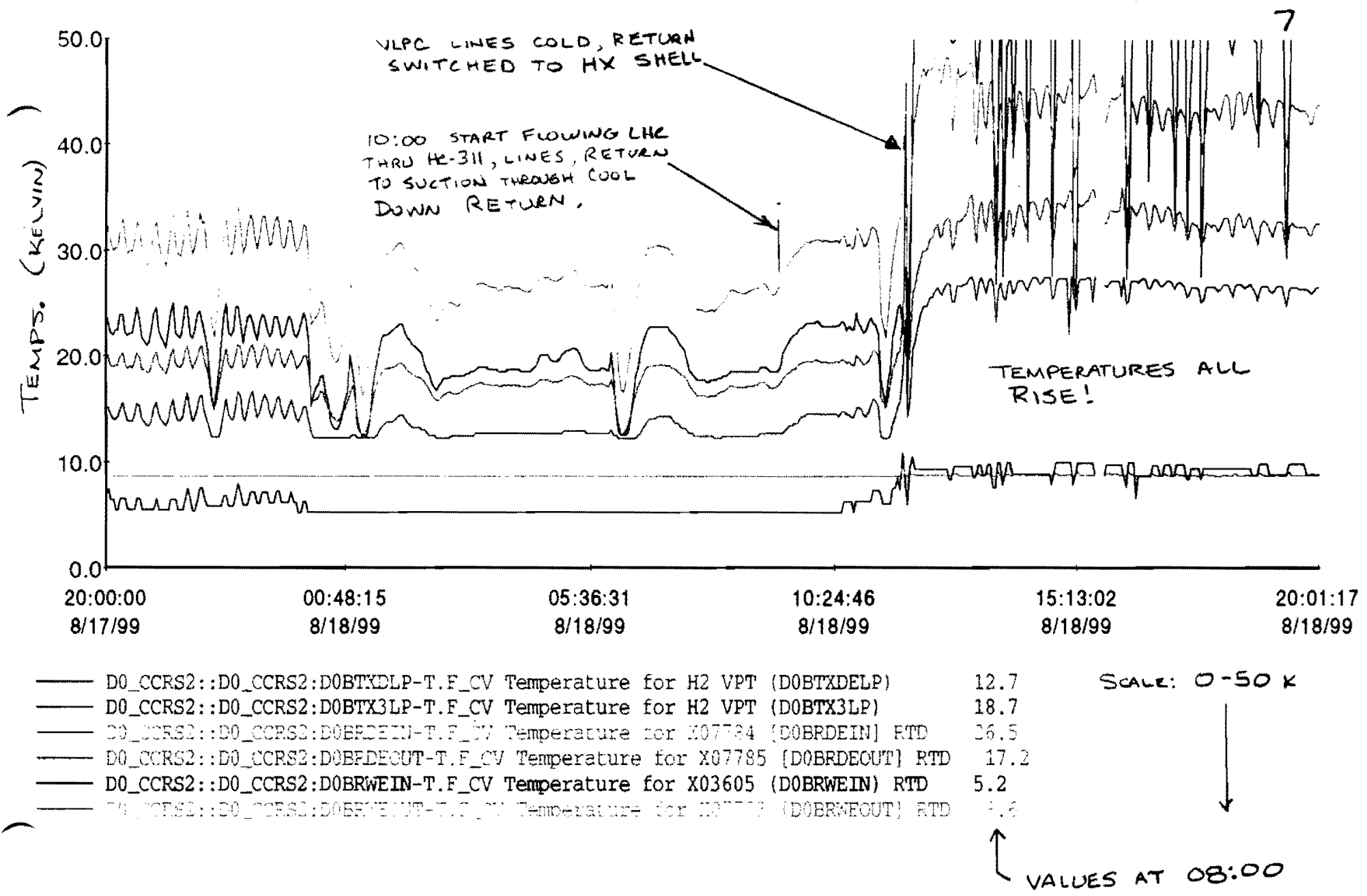

Figure 4: Contamination Problem from vLPC lines 


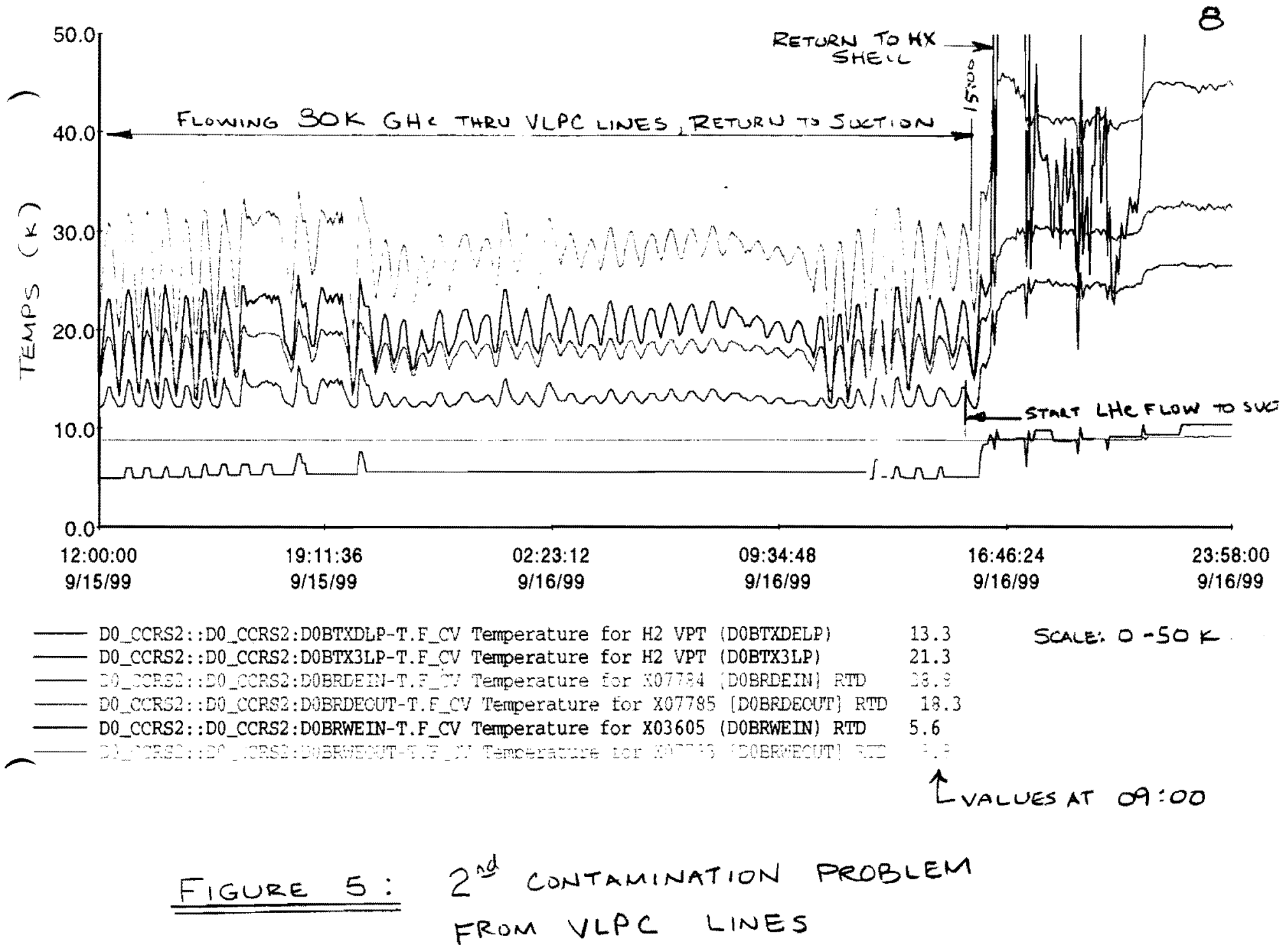


The heat leak for the supply line from the cool down heat exchanger to the bayonet can was 20 to 25 watts. The heat leak for the East line on the detector platform and back to the refrigerator was 40 to 50 watts. The corresponding West line was 30 to 40 watts. See Figure 6 below for the measured values versus total flow supplied.

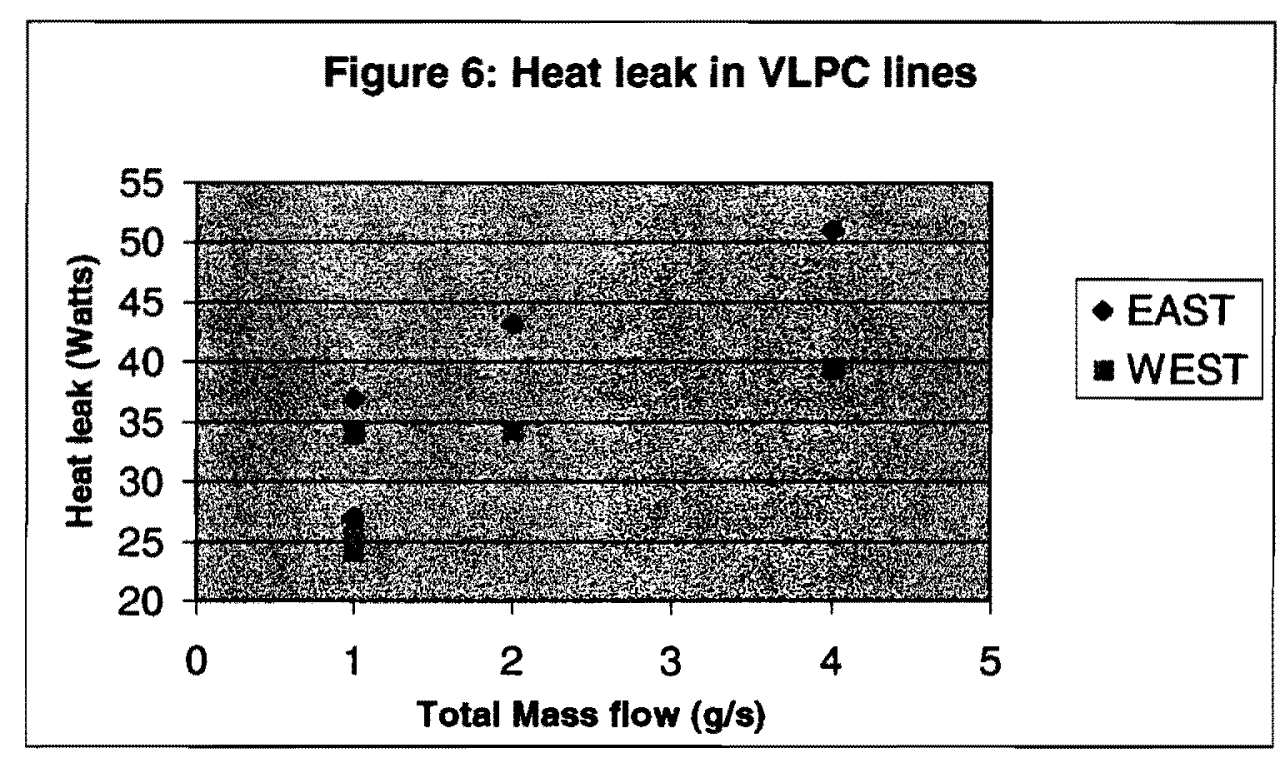

\section{Refrigerator Performance}

The refrigerator ran well with the exception of the contamination problems mentioned previously. During no extra load periods (Solenoid taking $3.0 \mathrm{~g} / \mathrm{s} \mathrm{liquid,} \mathrm{lead} \mathrm{flow}=0.14$ $\mathrm{g} / \mathrm{s}$ ) The dewar heater maintained liquid level by inputting 270 watts. The expansion engines would ride on their low limits and the heat exchanger was pulling 30 to $35 \mathrm{~g} / \mathrm{s}$ of compressor flow. See Figure 7 for the operating values.

On September 10, I put the dewar heater in manual at 400 watts. I put the expansion engines in manual at $800 \mathrm{rpm}$ for the dry and $600 \mathrm{rpm}$ for the wet. These conditions were such that the heat exchanger took full $60 \mathrm{~g} / \mathrm{s}$ compressor flow. We did not have the purifier in the system. The refrigerator was able to keep up and also liquified at 20 Liters $/ \mathrm{hr}$ (includes solenoid lead flow $=0.14 \mathrm{~g} / \mathrm{s}$ ). The solenoid transfer lines are about 39 watts (reference EN-457) and the solenoid itself is about 20 watts for zero current and this lead flow (reference EN-503). The dewar and u-tubes at the refrigerator are maybe another 20 watts. This gives a performance point of 480 watts plus $20 \mathrm{~L} / \mathrm{hr}$ liquefaction. The generic curve is 540 watts plus $20 \mathrm{~L} / \mathrm{hr}$. See Figure 8 for the test values and Figure 9 for a historical trend. The advertised generic operating curve for a STAR is shown in Figure 10 along with all measurements made.

For a five hour period 10:00 to 15:00 on September 13, I ran the dewar heater at 460 watts. The other conditions were the same as above. The liquid helium inventory was 
s.5364an D-ZERO HEAT-EXCHANGER AND LHE DEWAR

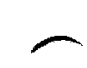

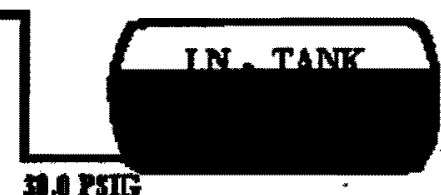

40.0 FIIS

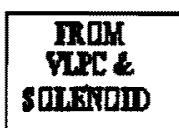

$\pi \times \mathrm{K}$

$79.9 \mathrm{X}$

\section{For2019.h Dorarie}

iss

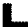

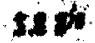

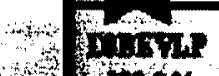

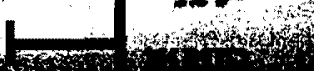

2615TE

$53 \mathrm{~K}$

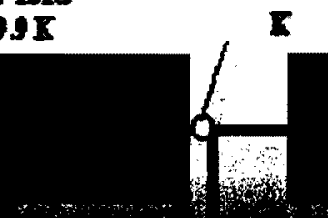

202 FIIG
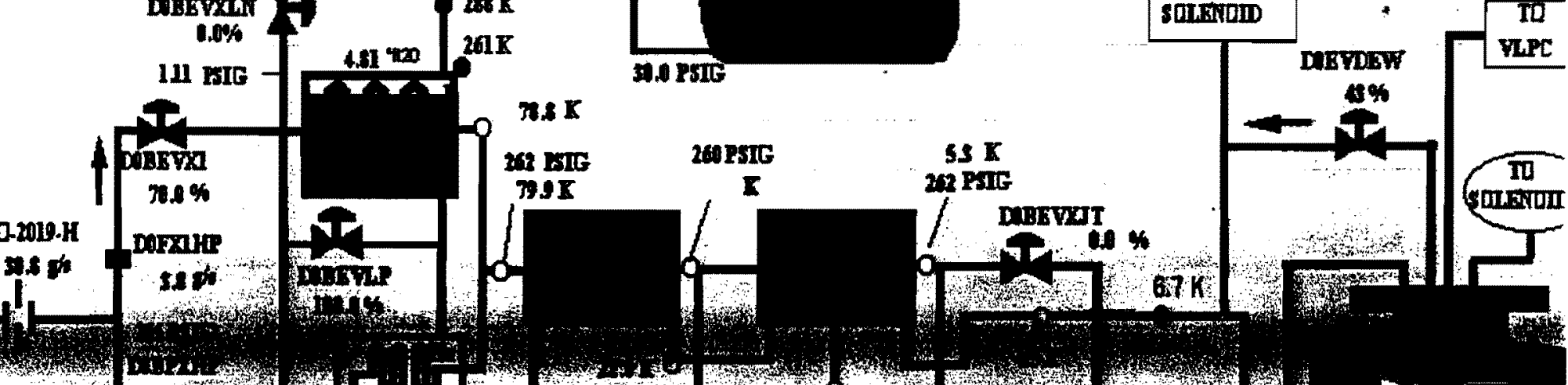

-

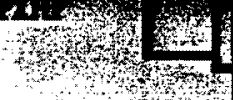

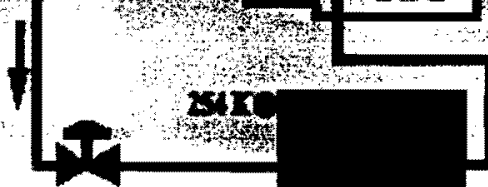

ming

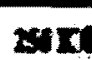

$104 \%$

os

.

\section{$0.5+115$}

DTR+10C

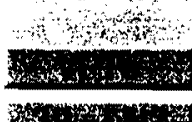

称

arom

IT

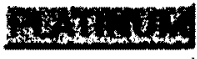

row

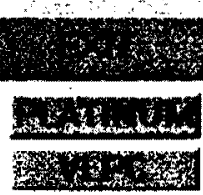

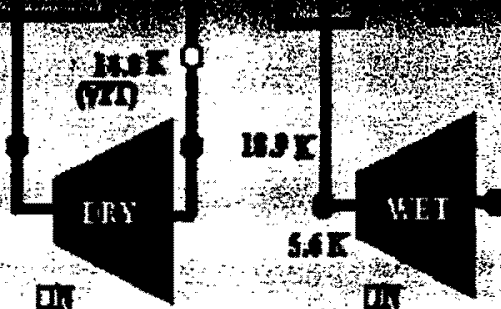

in.

4is Ix

और

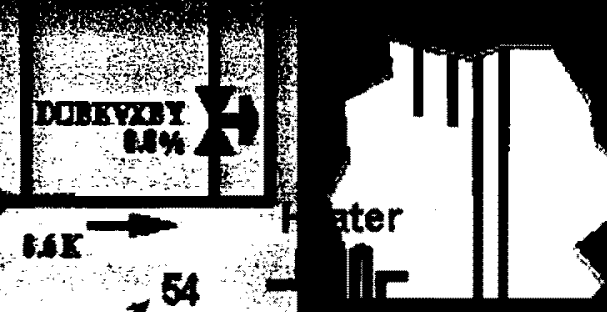

Watts

a rat
LNOTE: THS LOOP NOT TUNED.

TREND AVE.

$=270$ wata By Computer (>150L)

两
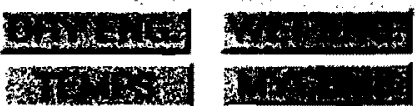

\section{.}

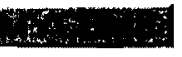

REFRIGERATOR LOAFING:

$$
\begin{aligned}
& \text { SOLENOIO } 23.0^{7} \mathrm{~S} \text { II0 } \\
& \text { AVG. HTR } \approx 270 \text { WhTS } \\
& \text { HTR DEW S.P. }=50 \mathrm{LI} \text { WET ENGINE } \\
& \text { SET POINT. }
\end{aligned}
$$

Figure 7 

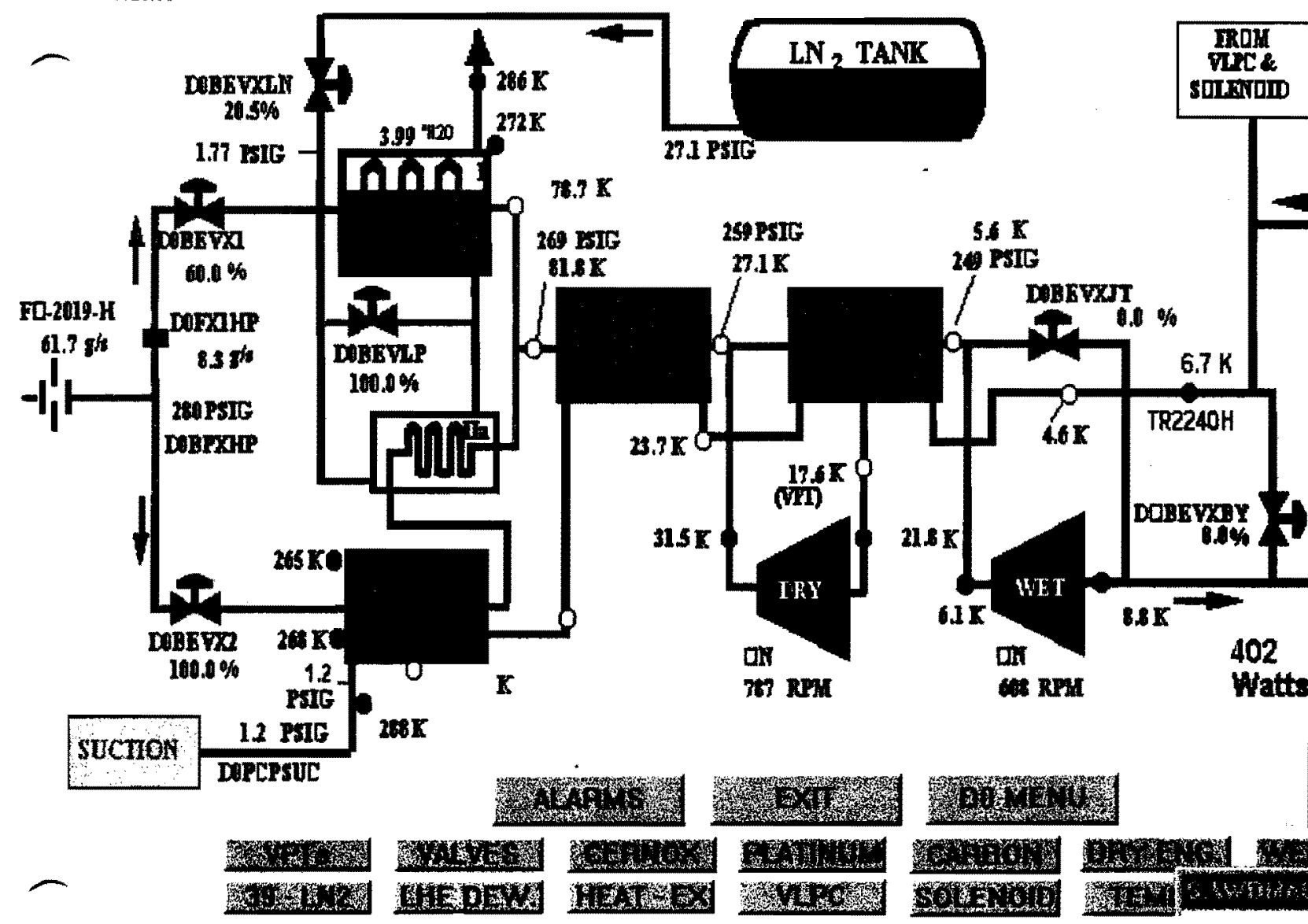


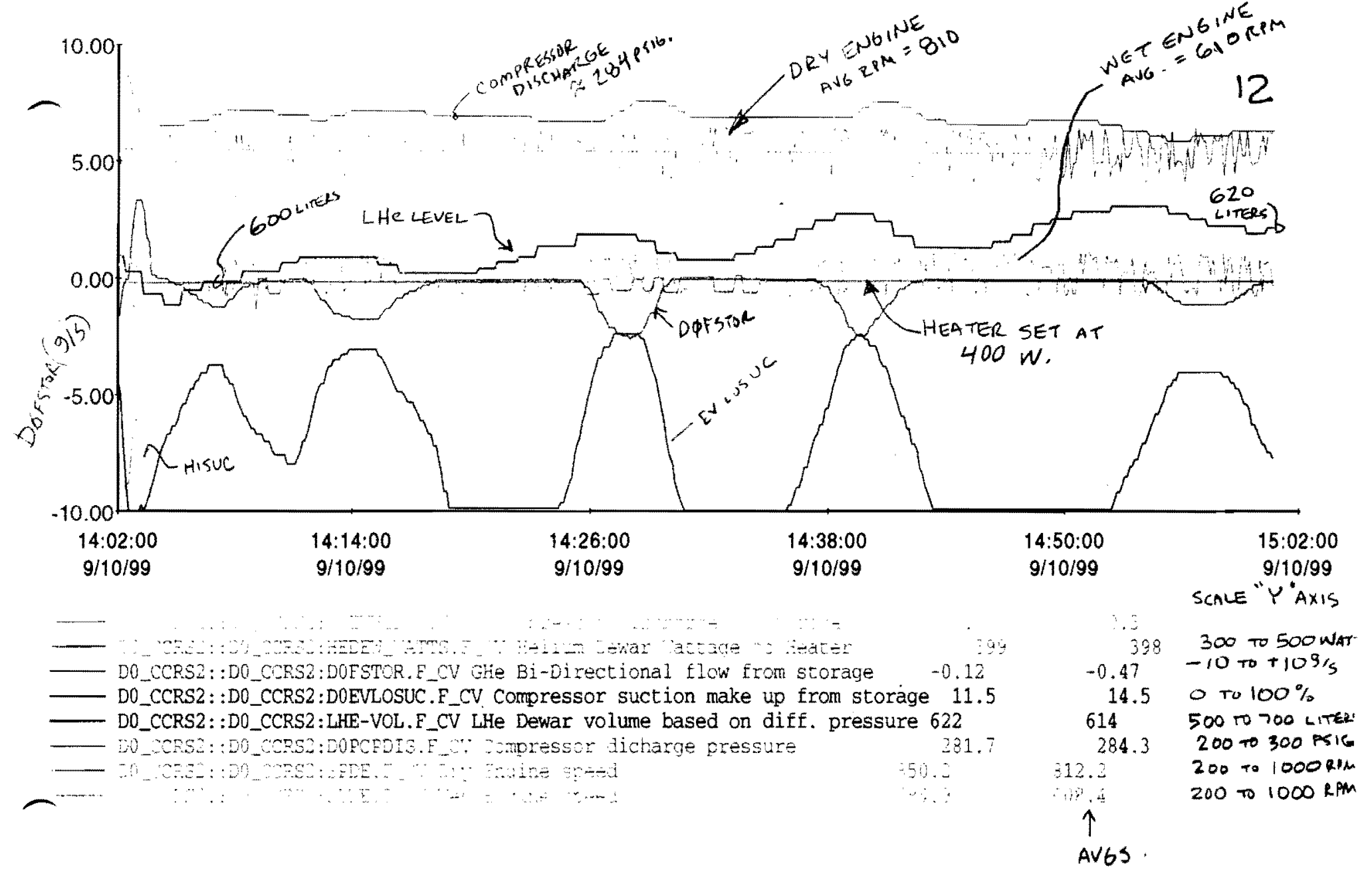

REFrigerator Capacity test

$$
\text { Figure } 9
$$




\section{D0 Refrigerator Performance}

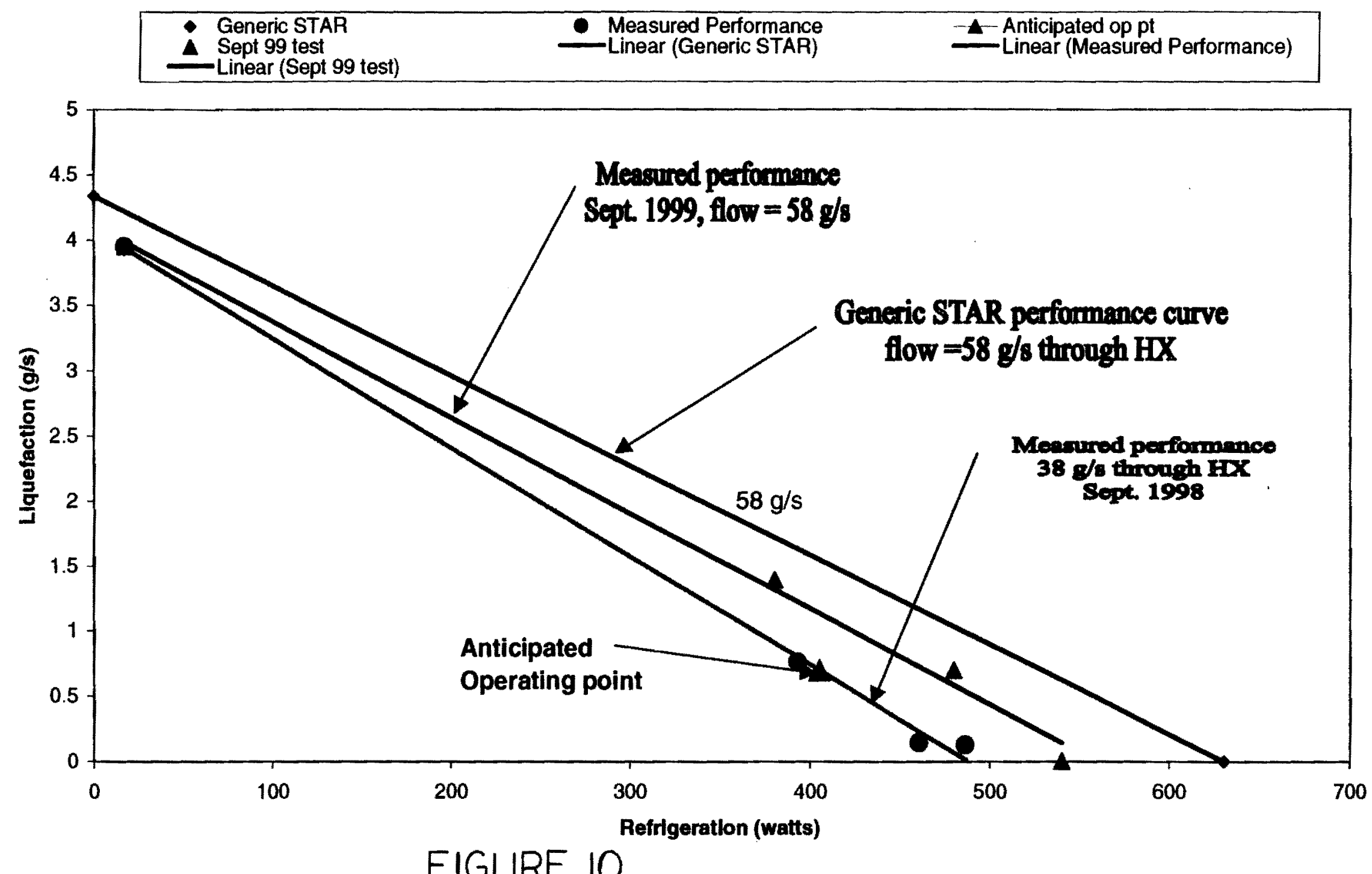


fairly flat at 600 Liters, we were not gaining. This gives a performance point of $460+39+20+20=540$ watts with negligible liquefaction. The generic curve is just over 600 watts with no liquefaction.

For the evening of September 13 the dewar heater was put in manual at 300 Watts. The solenoid was operated normally that evening with lead flow being at a total of $.72 \mathrm{~g} / \mathrm{s}$ at full current. The refrigerator ran just fine and accumulated liquid at 20 liquid liters per hour. This gives a rough operating point of $300+39+20+20=380$ watts plus 40 liters per hour liquefaction. The generic curve is 420 watts plus 40 liters per hour liquefaction.

\section{Margin:}

Loads:

$\begin{array}{ll}\text { Solenoid transfer line } & =40 \text { watts } \\ \text { Solenoid on detector } & =20 \text { watts } \\ \text { Solenoid lead flow } & =20 \mathrm{~L} / \mathrm{hr} \\ \text { Solenoid charging (transient) } & =20 \text { watts } \\ \text { VLPC transfer line East } & =45 \text { watts } \\ \text { VLPC transfer line West } & =35 \text { watts } \\ \text { VLPC cryostat, East } & =50 \text { watts } \\ \text { VLPC cryostat, West } & =50 \text { watts } \\ \text { VLPC cassettes, 102*1.2 } & =125 \text { watts } \\ \text { VLPC cass. heaters } 102 * 0.2 & =20 \text { watts } \\ \text { Refrigerator dewar, lines etc. } & =20 \text { watts }\end{array}$

Total $=405$ watts $+20 \mathrm{~L} / \mathrm{hr}+20$ watts (charging)

Margin $=(480$ watts $+20 \mathrm{~L} / \mathrm{hr}$ measured $)-(405$ watts $+20 \mathrm{~L} / \mathrm{hr})=75$ watts

The VLPC cryostat, cassettes, and cassette heaters are all estimated values. These components have no room for extra heat leak. As can be seen above, the refrigerator has enough capacity to handle the anticipated loads, but the margin for performance degradation is very slim. It will be troublesome to operate the refrigerator with this small margin. 